Int. J. Morphol.,

32(2):583-588, 2014

\title{
Anatomical Characteristics of Infra-Lamina Ridge in Chinese Population
}

\author{
Características Anatómicas del Puente Infra-laminar en la Población China
}

\author{
Xiao-he Li*; Yong-qiang Cai*; Xin Wang*; Shang Gao*\& Zhi-jun Li*
}

LI, X. H.; CAI, Y. Q.; WANG, X.; GAO, S. \& LI, Z. J. Anatomical characteristics of infra-lamina ridge in Chinese population. Int. J. Morphol., 32(2):583-588, 2014.

SUMMARY: The aim of our study was to observe the occurrence rate and morphological characteristics of Infra-Lamina ridge (ILR) in Chinese population and provide a comprehensive reference for its clinical implication. Vertebrae columns of 82 sets of Chinese adult skeletons were collected. The shape of ILR was classified into three types; the occurrence of it in different sides and sexes were counted. The length, width, thickness of ILR were measured using a caliper with $0.02 \mathrm{~mm}$ accuracy. The ILR was usually found to occur from C7 to L5, with its frequency higher from T8 to 12, and highest at T10-being up to 80.5\%. There was significant statistical difference to the occurrence rate by side, sex and vertebral level. The largest values in its length and width were from T9 to T12. The ILR at T10 was largest in dimensions, being $4.1 \pm 2.1 \mathrm{~mm}$ in length and $4.4 \pm 2.3 \mathrm{~mm}$ in width. The ILR is more frequently detected in female and at the left side, at the lower thoracic spine with a larger dimension.

KEY WORDS: Infra-lamina ridge; Vertebrae; Ossification; Ligamentum flavum; Morphological characteristics.

\section{INTRODUCTION}

Ossification of the ligamentum flavum (OCLF) can often be seen at the thoracic segment, particularly at the thoracolumbar junction (T10/11, T11/12 and T12/L1), which was first studied systematically most by Japanese researchers in Japanese population through X-ray, CT or MRI, with rare reports about its epidemiology beyond Japanese population (van Oostenbrugge et al., 1999). Maigne et al. (1992), had measured the frequency and size of ossification in the caudal attachments of ligamentum flavum at the thoracic spine in Caucasians and analyzed its pathology. During our study of the dry skeletons of the human spine, we found some osseous processes inferior to the laminae at certain spinal segments, which are similar to the ossification of the ligmentum flavern described by van Ostenbrugge et al. and Maigne et al., and are provisionally named as the infralaminae ridge in our article. To date, there are no reports about the occurrence of infra-lamina ridge (ILR) in Chinese population (He et al., 2005), its side and sex prevalence, types and dimensions, hence this paper is proposed to present our observation and measurement about the morphological characteristics, dimension, side and sex prevalence, and the distributional pattern of the ILR, the manifestation of ILR in skeleton, at various spinal segments in Chinese population; Its clinical implication is also investigated.

\section{MATERIAL AND METHOD}

Eighty-two sets of intact skeletons of vertebral column without severe degenerative changes were obtained from our anatomy department, with 42 sets being male skeletons and 40 sets being female skeletons and 12 cadavers (5 male and 7 female) with intact spine were also used. Their age is listed in Table I. The occurrence of ILR, which is defined as the presence of ILR longer than $1.5 \mathrm{~mm}$, was observed, and its presence on the left or right, male or female was respectively recorded. The shape was classified into three types (type A: inverted triangle; type B: saw-tooth shape; type C: spike shape) (Figs. 1, 2 and 3), the occurrence rate of which was calculated. The length, width and thickness of the ILR were measured using a caliper with $0.02 \mathrm{~mm}$ accuracy.

Data and statistical analysis. The acquired data were processed with the Statistical Package for the social sciences (SPSS, Inc, Chicago, IL). All the data were presented as mean $\pm \mathrm{SD}$. Comparison of the occurrence rate of the ILR between the left and right sides, between the male and female, and between the upper thoracic spine and lower thoracic spine by chi-square test all revealed significant statistical differences $(\mathrm{p}<0.01)$ Probability values of less than 0.05 were considered to be statistically significant. 


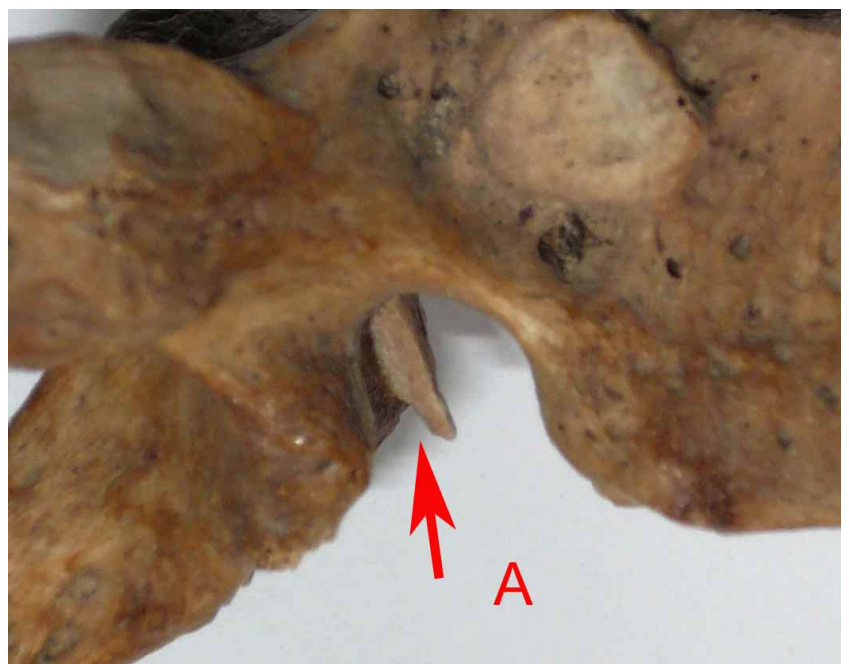

Fig. 1. Regional enlargement of infra- Lamina Ridge A: Type A.

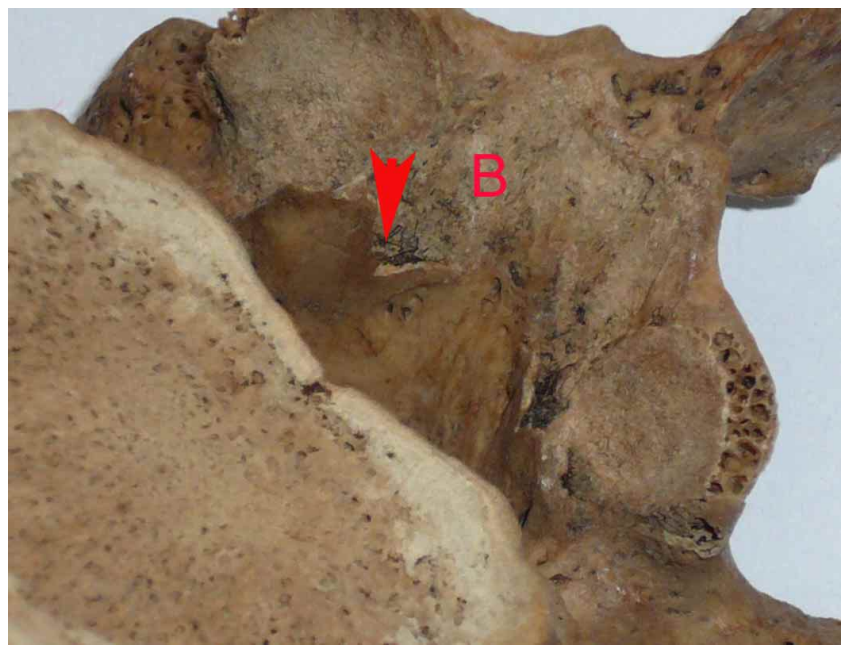

Fig. 2. Regional enlargement of infra- Lamina Ridge B: Type B.

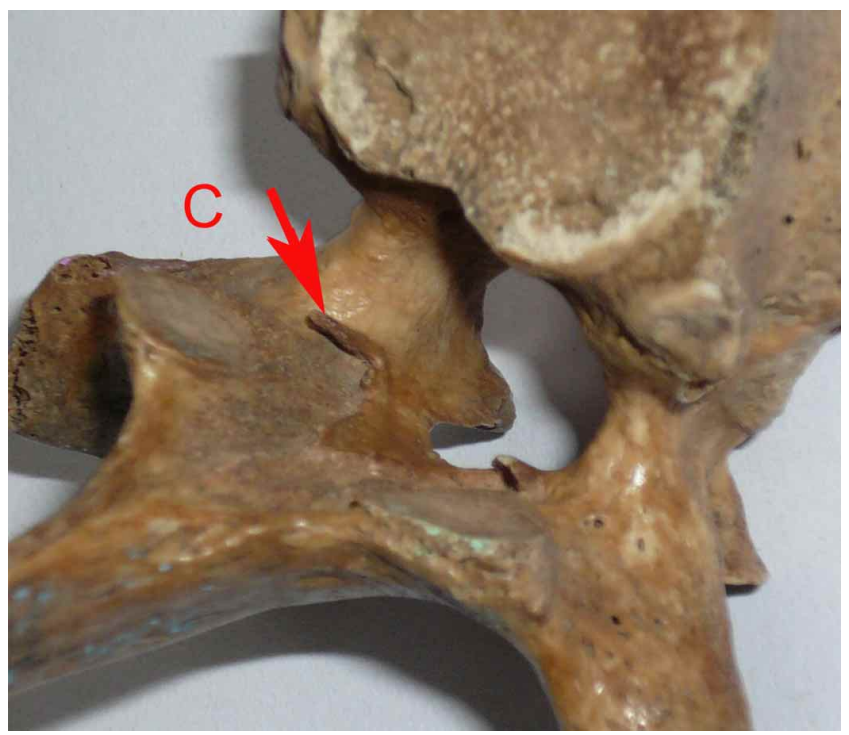

Fig. 3. Regional enlargement of infra- Lamina Ridge C: Type C.
Table I. The age of skeletons (n).

\begin{tabular}{cccc}
\hline Age (years) & Male & Female & Total \\
\hline$<25$ & 8 & 6 & 14 \\
$25-35$ & 7 & 6 & 13 \\
$36-45$ & 9 & 14 & 23 \\
$46-55$ & 13 & 8 & 21 \\
$>56$ & 5 & 6 & 11 \\
& 42 & 40 & 82
\end{tabular}

\section{RESULTS}

A total of 801 ILR were found in 1968 vertebrae. Data related to the length, width and thickness of ILR in each spinal segment were compared between the left and right, and the female and male using t test; No statistical differences were shown in terms of side and sex ( $p>0.05)$, therefore these data were combined for general analysis. Larger value of width and length of ILR were obtained from T9 to T12 segment, with its largest value being at T10. There was small fluctuation in the thickness of the ILR, ranging from $0.2 \mathrm{~mm}$ to $4.0 \mathrm{~mm}$. The maximal value of length as $12 \mathrm{~mm}$ was found at T11, width as $13.8 \mathrm{~mm}$ at T10, thickness as $4.0 \mathrm{~mm}$ at T4 (Table II).

The overall occurrence rate of the ILR, the occurrence rate of it with regard of sex and morphological type were listed in Figure 4. As the figure suggests, Type A and type $\mathrm{B}$ was more frequently present than type C; Type A was more often found in the upper thoracic spine (above T7) while type B appeared more frequently in the lower thoracic spine (below T7).

In male, the ILR appeared at C7 to L5 with the exception of L2; in female, it appeared at T2 to L5 with the exception of L3 and L4. The ILR occurred most frequently on T10 with the occurrence rate up to $80.5 \%$ (76.2\% in male and $85.0 \%$ in female). The ILR was rarely observed on cervical spine other than C7. In male, type A was frequently found at T1 to T8, type B at T9 to T12, while in female, type B was often found at T5 to T12 (Tables III and IV) (Fig. 4).

\section{DISCUSSION}

Anatomical Characteristics of ILR . The ILR is located at the junction of the antero inferolateral border of the vertebral lamina and the superior part of the base of the inferior articular process. It is connected with the linea aspera 
Table II. Data of ILR Mean \pm SD (min $\sim \max ) \operatorname{mm}(n=164)$.

\begin{tabular}{cccc}
\hline Vertebrae & Length & Width & Thickness \\
\hline C7 & $3.0 \pm 1.2(1.9 \sim 3.9)$ & $2.5 \pm 0.6(1.9 \sim 3.0)$ & $1.5 \pm 0.6(0.9 \sim 2.0)$ \\
T1 & $1.8 \pm 0.3(1.5 \sim 2.1)$ & $1.8 \pm 0.3(1.5 \sim 2.0)$ & $1.0 \pm 0.1(0.9 \sim 1.0)$ \\
T2 & $2.5 \pm 0.9(1.5 \sim 6.0)$ & $3.0 \pm 1.1(1.5 \sim 6.9)$ & $1.4 \pm 0.6(0.8 \sim 2.8)$ \\
T3 & $3.2 \pm 2.0(2.0 \sim 11.8)$ & $3.6 \pm 1.8(1.0 \sim 8.0)$ & $1.0 \pm 0.3(0.4 \sim 2.0)$ \\
T4 & $3.1 \pm 1.6(1.5 \sim 10.0)$ & $3.5 \pm 1.8(1.1 \sim 11.0)$ & $1.0 \pm 0.6(0.2 \sim 4.0)$ \\
T5 & $2.5 \pm 0.9(1.5 \sim 5.0)$ & $2.7 \pm 1.0(1.0 \sim 6.1)$ & $0.8 \pm 0.2(0.5 \sim 1.5)$ \\
T6 & $3.1 \pm 1.2(1.5 \sim 7.0)$ & $3.1 \pm 1.4(1.5 \sim 8.0)^{*}$ & $0.9 \pm 0.4(0.5 \sim 2.0)$ \\
T7 & $3.0 \pm 1.0(1.5 \sim 5.1)$ & $3.1 \pm 1.0(1.0 \sim 5.2)^{*} \#$ & $0.9 \pm 0.4(0.3 \sim 2.0)$ \\
T8 & $3.0 \pm 1.4(1.5 \sim 10.2)^{*} \#$ & $3.5 \pm 1.5(1.2 \sim 10.0)$ & $0.9 \pm 0.4(0.3 \sim 1.9)$ \\
T9 & $4.0 \pm 2.2(2.0 \sim 10.0)$ & $4.3 \pm 2.1(1.1 \sim 10.9)$ & $1.1 \pm 0.6(0.3 \sim 3.0)$ \\
T10 & $4.1 \pm 2.1(1.5 \sim 11.9)$ & $4.4 \pm 2.3(1.5 \sim 13.8)$ & $1.2 \pm 0.6(0.6 \sim 3.2)$ \\
T11 & $3.8 \pm 1.5(1.6 \sim 12.0)$ & $4.3 \pm 2.1(1.6 \sim 12.4)$ & $1.1 \pm 0.5(0.4 \sim 3.0) * \#$ \\
T12 & $3.7 \pm 1.9(1.5 \sim 9.8)$ & $4.3 \pm 2.0(1.0 \sim 12.0)$ & $1.0 \pm 0.5(0.3 \sim 2.5)$ \\
L1 & $2.5 \pm 0.9(1.5 \sim 6.0)^{*}$ & $3.0 \pm 1.1(1.5 \sim 7.0)$ & $1.4 \pm 0.6(0.8 \sim 3.0)$ \\
L2 & $3.0 \pm 1.4(2.0 \sim 3.9)$ & $3.5 \pm 0.7(2.8 \sim 4.1)$ & $0.8 \pm 0.1(0.7 \sim 0.9) \#$ \\
L3 & $1.9 \pm 0.0(1.9 \sim 1.9)$ & $2.0 \pm 0.0(2.0 \sim 2.0)$ & $2.1 \pm 0.0(2.1 \sim 2.1)$ \\
L4 & $2.7 \pm 1.2(2.0 \sim 4.1)$ & $3.6 \pm 0.6(2.9 \sim 3.8)$ & $1.3 \pm 0.6(0.8 \sim 2.0) \#$ \\
L5 & $2.9 \pm 0.8(2.1 \sim 4.1)^{*}$ & $3.7 \pm 1.3(1.9 \sim 5.0)^{*}$ & $1.0 \pm 0.1(0.9 \sim 1.1)$ \\
Total & $3.4 \pm 1.7(1.5 \sim 12.0)$ & $3.8 \pm 1.9(1.0 \sim 13.8)$ & $1.1 \pm 0.5(0.2 \sim 4.0)$ \\
\hline
\end{tabular}

* There is statistical significance for sexuality $(\mathrm{p}<0.05)$, \# There is statistical significance for both sides $(\mathrm{p}<0.05)$.

Table III. The occurrence rate and cases on three types of ILR in male.

\begin{tabular}{|c|c|c|c|c|c|c|c|c|}
\hline \multirow{2}{*}{ Vertebrae } & \multirow{2}{*}{\multicolumn{4}{|c|}{ Left \% (n) }} & \multicolumn{4}{|c|}{ Right \% (n) } \\
\hline & & & & Total $^{\#}$ & A* & B* & $\mathrm{C}^{*}$ & Total\# \\
\hline $\mathrm{C}_{7}$ & $100.0(2)$ & $0.0(0)$ & $0.0(0)$ & $4.8(2)$ & $100.0(2)$ & $0.0(0)$ & $0.0(0)$ & $4.8(2)$ \\
\hline $\mathrm{T}_{1}$ & $0.0(0)$ & $0.0(0)$ & $100.0(2)$ & $4.8(2)$ & $0.0(0)$ & $0.0(0)$ & $100.0(2)$ & $4.8(2)$ \\
\hline $\mathrm{T}_{2}$ & $33.3(2)$ & $33.3(2)$ & $33.3(2)$ & $14.0(6)$ & $0.0(0)$ & $0.0(0)$ & $100.0(4)$ & $9.5(4)$ \\
\hline $\mathrm{T}_{3}$ & $50.0(7)$ & $35.7(5)$ & $14.3(2)$ & $33.3(14)$ & $30.0(3)$ & $30.0(3)$ & $40.0(4)$ & $23.8(10)$ \\
\hline $\mathrm{T}_{4}$ & $33.3(4)$ & $33.3(4)$ & $33.3(4)$ & $28.6(12)$ & $38.5(5)$ & $38.5(5)$ & $23.0(3)$ & $30.9(13)$ \\
\hline $\mathrm{T}_{5}$ & $64.3(9)$ & $13.4(3)$ & $14.3(2)$ & $33.3(14)$ & $46.7(7)$ & $20.0(3)$ & $33.3(5)$ & $35.7(15)$ \\
\hline $\mathrm{T}_{6}$ & $63.9(7)$ & $38.5(5)$ & $7.6(1)$ & 30.9 (13) & $58.3(7)$ & $16.7(2)$ & $25.0(3)$ & $28.6(12)$ \\
\hline $\mathrm{T}_{7}$ & $61.5(8)$ & $30.8(4)$ & $7.7(1)$ & 30.9 (13) & $53.9(7)$ & $30.8(4)$ & $15.3(2)$ & 30.9 (13) \\
\hline $\mathrm{T}_{8}$ & $42.1(8)$ & $57.9(11)$ & $0.0(0)$ & $45.2(19)$ & $47.1(8)$ & $41.2(7)$ & $11.7(2)$ & $40.5(17)$ \\
\hline $\mathrm{T}_{9}$ & $41.4(12)$ & $48.3(14)$ & $10.3(3)$ & $69.1(29)$ & $66.1(18)$ & $29.7(8)$ & $3.6(1)$ & $64.3(27)$ \\
\hline $\mathrm{T}_{10}$ & $36.7(11)$ & $63.3(19)$ & $0.0(0)$ & $72.1(30)$ & $27.6(8)$ & $72.4(21)$ & $0.0(0)$ & $69.1(29)$ \\
\hline $\mathrm{T}_{11}$ & $33.3(9)$ & $66.7(18)$ & $0.0(0)$ & $64.3(27)$ & $34.8(8)$ & $65.2(15)$ & $0.0(0)$ & $54.8(23)$ \\
\hline $\mathrm{T}_{12}$ & $28.6(6)$ & $71.4(15)$ & $0.0(0)$ & $50.0(21)$ & $35.0(7)$ & $55.0(11)$ & $10.0(2)$ & $47.6(20)$ \\
\hline $\mathrm{L}_{1}$ & $22.2(2)$ & $66.7(6)$ & $11.1(1)$ & $21.4(9)$ & $57.1(4)$ & $28.6(2)$ & $14.3(1)$ & $16.7(7)$ \\
\hline $\mathrm{L}_{2}$ & $0.0(0)$ & $0.0(0)$ & $0.0(0)$ & $0.0(0)$ & $0.0(0)$ & $0.0(0)$ & $0.0(0)$ & $0.0(0)$ \\
\hline $\mathrm{L}_{3}$ & $100.0(1)$ & $0.0(0)$ & $0.0(0)$ & $2.4(1)$ & $0.0(0)$ & $0.0(0)$ & $0.0(0)$ & $0.0(0)$ \\
\hline $\mathrm{L}_{4}$ & $100.0(2)$ & $0.0(0)$ & $0.0(0)$ & $4.8(2)$ & $100.0(1)$ & $0.0(0)$ & $0.0(0)$ & $2.4(1)$ \\
\hline $\mathrm{L}_{5}$ & $100.0(1)$ & $0.0(0)$ & $0.0(0)$ & $2.4(1)$ & $100.0(1)$ & $0.0(0)$ & $0.0(0)$ & $2.4(1)$ \\
\hline
\end{tabular}

*(The case of one type of ILR / The case of ILR) X 100\%; \#(The case of one type of ILR / Sample size ) X 100\% 


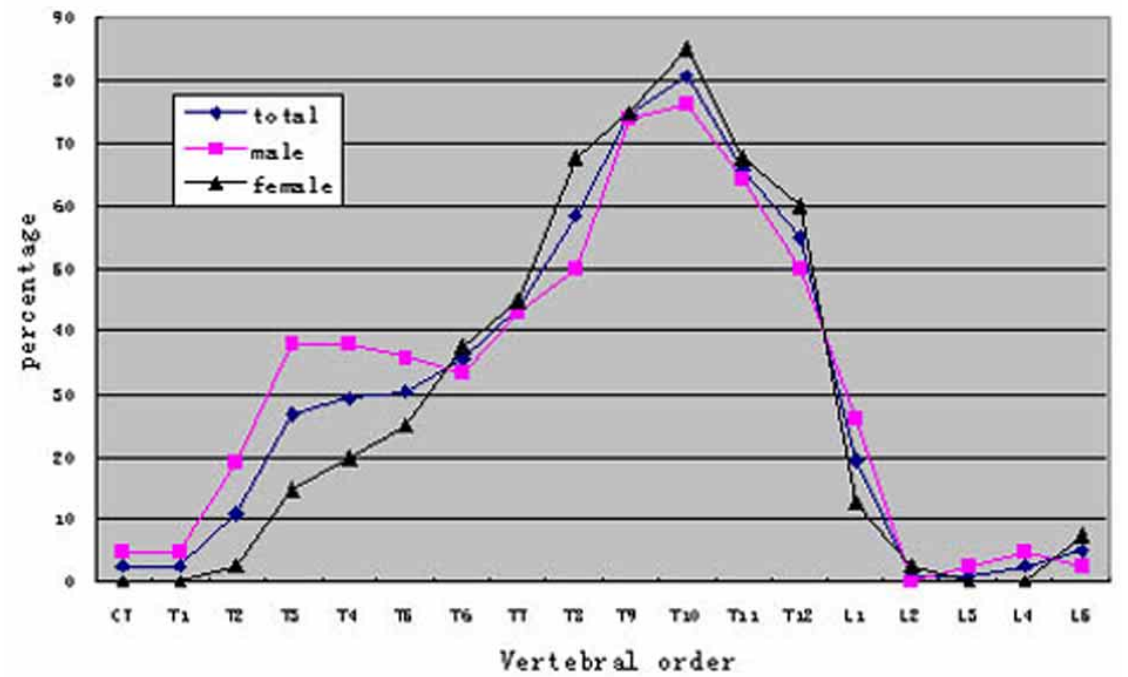

Fig. 4. The total occurence rate of Infra-Lamina Ridge.

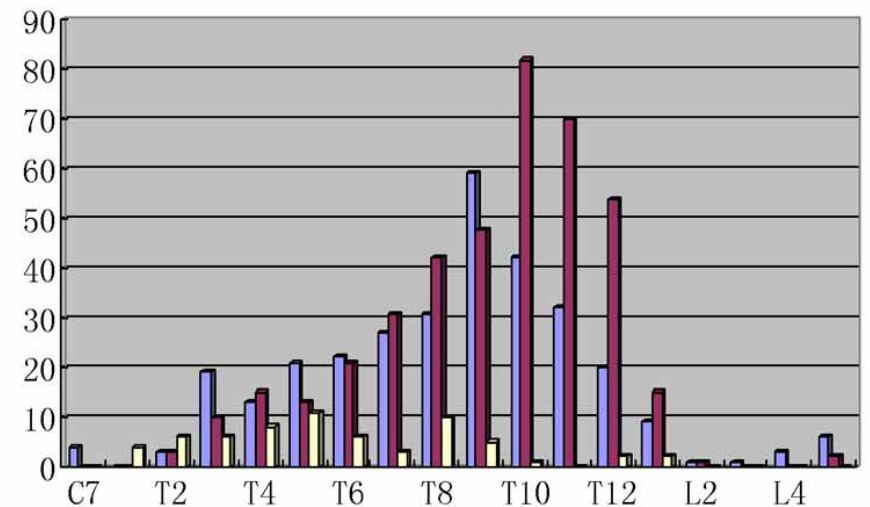

Type A

Type B $\square$ Type C

Fig. 5. The occurrence number on Infra-Lamina Ridge.

Table IV. The occurrence rate and cases on three types of ILR in female.

\begin{tabular}{ccccccccc}
\hline \multirow{2}{*}{ Vertebrae } & \multicolumn{4}{c}{ Left \% (n) } & \multicolumn{3}{c}{ Right \% (n) } \\
\cline { 2 - 8 } & $\mathbf{A}^{*}$ & $\mathbf{B}^{*}$ & $\mathbf{C}^{*}$ & Total $^{\#}$ & $\mathbf{A}^{*}$ & $\mathbf{B}^{*}$ & $\mathbf{C}^{*}$ & Total \# \\
\hline $\mathrm{C}_{7}$ & $0.0(0)$ & $0.0(0)$ & $0.0(0)$ & $0.0(0)$ & $0.0(0)$ & $0.0(0)$ & $0.0(0)$ & $0.0(0)$ \\
$\mathrm{T}_{1}$ & $0.0(0)$ & $0.0(0)$ & $0.0(0)$ & $0.0(0)$ & $0.0(0)$ & $0.0(0)$ & $0.0(0)$ & $0.0(0)$ \\
$\mathrm{T}_{2}$ & $100.0(1)$ & $0.0(0)$ & $0.0(0)$ & $2.5(1)$ & $0.0(0)$ & $100.0(1)$ & $0.0(0)$ & $2.5(1)$ \\
$\mathrm{T}_{3}$ & $60.0(3)$ & $40.0(2)$ & $0.0(0)$ & $12.5(5)$ & $100.0(6)$ & $0.0(0)$ & $0.0(0)$ & $15.0(6)$ \\
$\mathrm{T}_{4}$ & $33.3(2)$ & $50.0(3)$ & $16.7(1)$ & $15.0(6)$ & $40.0(2)$ & $60.0(3)$ & $0.0(0)$ & $12.5(5)$ \\
$\mathrm{T}_{5}$ & $12.5(1)$ & $50.0(4)$ & $37.5(3)$ & $20.0(8)$ & $50.0(4)$ & $37.5(3)$ & $0.0(0)$ & $20.0(8)$ \\
$\mathrm{T}_{6}$ & $25.0(3)$ & $58.3(7)$ & $16.7(2)$ & $30.0(12)$ & $41.7(5)$ & $58.3(7)$ & $12.5(1)$ & $30.0(12)$ \\
$\mathrm{T}_{7}$ & $33.3(6)$ & $66.7(1)$ & $0.0(0)$ & $45.0(18)$ & $35.3(6)$ & $64.7(11)$ & $0.0(0)$ & $42.5(17)$ \\
$\mathrm{T}_{8}$ & $37.0(10)$ & $37.0(1)$ & $26.0(7)$ & $67.5(27)$ & $25.0(5)$ & $70.0(14)$ & $0.0(0)$ & $50.0(20)$ \\
$\mathrm{T}_{9}$ & $46.7(14)$ & $53.3(1)$ & $0.0(0)$ & $75.0(30)$ & $57.7(15)$ & $38.5(10)$ & $5.0(1)$ & $65.0(26)$ \\
$\mathrm{T}_{10}$ & $30.3(10)$ & $66.7(2)$ & $3.0(1)$ & $82.5(33)$ & $39.4(13)$ & $60.6(20)$ & $3.8(1)$ & $82.5(33)$ \\
$\mathrm{T}_{11}$ & $30.8(8)$ & $69.2(1)$ & $0.0(0)$ & $65.0(26)$ & $26.9(7)$ & $73.1(19)$ & $0.0(0)$ & $65.0(26)$ \\
$\mathrm{T}_{12}$ & $29.4(5)$ & $70.6(1)$ & $0.0(0)$ & $42.5(17)$ & $11.1(2)$ & $88.9(16)$ & $0.0(0)$ & $45.0(18)$ \\
$\mathrm{L}_{1}$ & $40.0(2)$ & $60.0(3)$ & $0.0(0)$ & $12.5(5)$ & $20.0(1)$ & $80.0(4)$ & $0.0(0)$ & $12.5(5)$ \\
$\mathrm{L}_{2}$ & $100.0(1)$ & $0.0(0)$ & $0.0(0)$ & $2.5(1)$ & $0.0(0)$ & $100.0(1)$ & $0.0(0)$ & $2.5(1)$ \\
$\mathrm{L}_{3}$ & $0.0(0)$ & $0.0(0)$ & $0.0(0)$ & $0.0(0)$ & $0.0(0)$ & $0.0(0)$ & $0.0(0)$ & $0.0(0)$ \\
$\mathrm{L}_{4}$ & $0.0(0)$ & $0.0(0)$ & $0.0(0)$ & $0.0(0)$ & $0.0(0)$ & $0.0(0)$ & $0.0(0)$ & $0.0(0)$ \\
$\mathrm{L}_{5}$ & $100.0(3)$ & $0.0(0)$ & $0.0(0)$ & $7.5(3)$ & $33.3(1)$ & $66.7(2)$ & $0.0(0)$ & $7.5(3)$ \\
\hline
\end{tabular}

*(The case of one type of ILR / The case of ILR) X100; \#(The case of one type of ILR / Sample size) X 100\% 
of the ligamenta flava. The characteristics of ILR are as follows: 1) It diminishes in width form the upper side down; it is flat in anteroposterior view with the tip pointing to the vertebral canal; 2) The shapes of ILR can be defined as three types: inverted triangle, saw-tooth shape and spike shape; 3) The anterior surface of it is smooth while the posterior surface is rough; The outer margin is blunt while the inner margin is sharp and irregular; 4) It usually appears continuously on multiple segments of the vertebral column; sometimes it appears in intermittent segments, or even appears in one vertebra and one side of the vertebra; 5) There is a bony process on the lower vertebra that corresponds to the infra-lamina ridge. This bony process is projected from the base of the superior articular process with an irregular shape and its superior margin fused with the inner margin of infra-lamina ridge. This bony process is often present on both sides of the vertebra with an overall occurrence rate higher than that of the infra-lamina ridge. Since there is no standard anatomical terminology that can be retrieved in literature to our best knowledge, we name it as the medial ridge of the superior articular process, just as we do to the infra-lamina ridge.

The relationship between the infra-lamina ridge and the adjacent anatomical structures. Similar to Maigne's report about ossifications in the caudal attachments of the ligamentum flavum of the thoracic spine (Maigne et al.), the ILR is more frequently present in the lower thoracic spine with a relatively larger dimension, which is probably associated with the higher mobility of the small joints. There is a groove between the posterior aspect of the ILR and the inferior articular surface, where the tip of the superior articular process is wedged, probably leading to impediment of the mobility of small joints (Ruiz Santiago et al., 1997; Okuda et al., 2004). In addition, the ILR was found in 8 of the 12 cadavers, which is in contact with the anterior aspect of the articular capsule, leading to swelling of the capsule, and further to narrowness of the corresponding vertebral canal and compression of the adjacent nerve root (Yoshida et al., 1992; Xiong et al., 2001; Mak et al., 2002). It could be an important etiology in the clinically detected spinal stenosis.

The relationship between the ILR and OCFL. When observed in 8 cadavers under the magnification coupe ( $¥ 10$ ), the ligamentum flavum was found to cover the infra-lamina ridge with a hard texture, and there was a trace of ossification at its lateral margins. Therefore, the question arises: Is the ILR a structure where the ligamentum flavum is attached, or is it vestige of ossification of the ligamentum flavum? It has been reported in literature that OCLF most frequently happens in the lower thoracic spine where there is a large range of mobility of small joints and it often started from the lateral margins of the ligamentum flavum with the articular capsule involved (Pascal-Mousselard et al., 1998), which is similar to our observation. We also found in the cadavers that the infra-lamina ridge fused with the medial ridge of the superior articular process, together assuming an elongate shape, located lateral to the ligamentum flavum, which was similar to what we found in the skeletons. Therefore, we assume that the infra-lamina ridge and the medial ridge of the superior articular process are vestiges of ossification caused by the repetitive local strains and repair of the ligamentum flavum. The two ridges can be detected by various imaging modalities, which should be paid enough attention when the OCFL is to be diagnosed.

\section{CONCLUSION}

It is fundamentally important to observe the occurrence rate and morphological characteristics of InfraLamina Ridge (ILR) in Chinese population. In Chinese normal individuals, The ILR is more frequently detected in female and at the left side, and at the lower thoracic spine with a larger dimension.

LI, X. H.; CAI, Y. Q.; WANG, X.; GAO, S. \& LI, Z. J. Características anatómicas del puente infra-laminar en la población de China. Int. J. Morphol., 32(2):583-588, 2014.

RESUMEN: El objetivo de nuestro estudio fue observar la tasa de incidencia y características morfológicas del puente infralaminar (PIL) en la población china y ofrecer una referencia completa por su implicación clínica. Se utilizaron 82 series de vértebras pertenecientes a esqueletos adultos chinos. La forma del PIL se clasificó en tres tipos; además se cuantificó la presenciade la misma en diferentes lados y sexos. La longitud, ancho y grosor del PIL se midieron utilizando un caliper con 0,02 mm de precisión. Se encontró que el PIL por lo general se producía desde C7 a L5, con una mayor frecuencia entre T8 y T12, la más alta en T10 donde alcanzó el 80,5\%. No hubo diferencia estadísticamente significativa en la tasa de ocurrencia según lado, sexo y el nivel de la vértebra. Los mayores valores de longitud y ancho fueron de T9 a T12. El PIL en T10 tuvo las mayores dimensiones, con una longitud de 4,1 $\pm 2,1 \mathrm{~mm}$ y ancho de $4,4 \pm 2,3 \mathrm{~mm}$. El PIL se detecta con mayor frecuencia en mujeres y la lado izquierdo, con una mayor dimensión en la columna torácica inferior.

PALABRAS CLAVE: Puente infra-laminar; Vértebras; Osificación; Ligamento amarillo; Características morfológicas. 


\section{REFERENCES}

He, S.; Hussain, N.; Li, S. \& Hou, T. Clinical and prognostic analysis of ossified ligamentum flavum in a Chinese population. $J$. Neurosurg. Spine, 3(5):348-54, 2005.

Maigne, J. Y.; Ayral, X. \& Guérin-Surville, H. Frequency and size of ossifications in the caudal attachments of the ligamentum flavum of the thoracic spine: Role of rotatory strains in their development: An anatomic study of 121 spines. Surg. Radiol. Anat., 14(2):119-24, 1992.

Mak, K. H.; Mak, K. L. \& Gwi-Mak, E. Ossification of the ligamentum flavum in the cervicothoracic junction: case report on ossification found on both sides of the lamina. Spine (Phila. Pa. 1976), 27(1):E11-4, 2002.

Okuda, T.; Baba, I.; Fujimoto, Y.; Tanaka, N.; Sumida, T.; Manabe, H.; Hayashi, Y. \& Ochi, M. The pathology of ligamentum flavum in degenerative lumbar disease. Spine (Phila. Pa. 1976), 29(15):1689-97, 2004.

Pascal-Mousselard, H.; Smadja, D.; Cabre, P.; Raynaud, M. \& Catonne, Y. Ossification of the ligamenta flava with severe myelopathy in a black patient. A case report. Spine (Phila. Pa. 1976), 23(14):1607-8, 1998.

Ruiz Santiago, F.; Alcázar Romero, P. P.; López Machado, E. \& Garcia Espona, M. A. Calcification of lumbar ligamentum flavum and facet joints capsule. Spine (Phila. Pa. 1976), 22(15):1734-5, 1997.

van Oostenbrugge, R. J.; Herpers, M. J. \& de Kruijk, J. R. Spinal cord compression caused by unusual location and extension of ossified ligamenta flava in a Caucasian male. A case report and literature review. Spine (Phila. Pa. 1976), 24(5):486-8, 1999.

Warwick, R. \& Williams, P. L. Grey's Anatomy. $35^{\text {th }}$ ed. London, Longman Group Ltd., 1973. pp.237-45.

Xiong, L.; Zeng, Q. Y. \& Jinkins, J. R. CT and MRI characteristics of ossification of ligamenta flava in the thoracic spine. Eur. Radiol., 11(9):1798-802, 2001.

Yoshida, M.; Shima, K.; Taniguchi, Y.; Tamaki, T. \& Tanaka, T. Hypertrophied ligamentum flavum in lumbar spinal canal stenosis. Pathogenesis and morphologic and immunohistochemical observation. Spine (Phila. Pa. 1976), 17(11):1353-60, 1992.
Correspondence to:

Zhi-jun Li

Department of Anatomy,

Basic Medical College

Inner Mongolia Medical University

Jinshan Economic Development Zone

Huhhot 010110

Inner Mongolia

P. R. CHINA

Email: 798242742@qq.com

Received: 17-01-2013

Accepted: 19-11-2013 